\section{Detection of human hematopoietic stem cell engraftment in the livers of adult immunodeficient mice by an optimized flow cytometric method}

\author{
Nicole L. Varga, ${ }^{1}$ Alicia Bárcena, ${ }^{1,2}$ \\ Marina E. Fomin, ${ }^{1}$ Marcus O. Muench ${ }^{1,3}$ \\ 'Blood Systems Research Institute, San \\ Francisco; \\ 2Institute for Regeneration Medicine, \\ Department of Obstetrics, Gynecology, \\ and Reproductive Sciences, University of \\ California, San Francisco; \\ ${ }^{3}$ Department of Laboratory Medicine and \\ the Liver Center, University of California, \\ San Francisco, California, USA
}

\section{Abstract}

Immunodeficient NOD.Cg-Prkdc scid Il2rgtmlWjl SzJ (NSG) mice are a valuable resource to study human hematopoietic stem cells. Prolonged multilineage hematopoiesis indicates stem cell engraftment and generally is measured by flow cytometry. In this study, we took advantage of the multi-parameter detection afforded by modern flow cytometers to optimize detection of human hematopoiesis in NSG mice. Antigens widely expressed by mouse or human cells were evaluated as markers to distinguish mixtures of these cells to optimize and test the limits of chimerism detection. The bone marrow, spleen, and liver of NSG mice transplanted with human hematopoietic cells were analyzed for evidence of engraftment.

Mouse bone marrow cells were best marked for exclusion by staining with a combination of CD45, TER-119, and anti-H-2K $\mathrm{K}^{\mathrm{d}}$ monoclonal antibodies, whereas live human cells were most accurately identified by elimination of cell doublets and positive staining for CD59. Human stem cells $\left(\mathrm{CD} 34^{++} \mathrm{CD} 133^{+} \mathrm{CD} 38^{\text {low }}\right)$ and progenitors were detected in the bone marrow and liver, but not in the spleen. An unusual pattern of myeloid antigen expression was detected in the bone marrow and $\mathrm{CD}^{+}{ }^{+} \mathrm{CD} 4{ }^{+} \mathrm{CD} 8{ }^{+} \mathrm{T}$-cells were detected in the spleen. We concluded that multicolor flow cytometric analysis that clearly distinguishes mouse and human cells offers accurate detection of human chimerism in NSG mice. Human hematopoiesis can be detected in the bone marrow and liver of NSG mice with Tlymphopoiesis, possibly occurring in the spleen.

\section{Introduction}

Hematopoiesis is maintained by a pool of stem cells capable of self-renewal, extensive proliferation, and multilineage differentiation into erythroid, myeloid, and lymphoid cells. Although many markers have been identified that help to isolate enriched populations of hematopoietic stem cells such as CD34, CD133, and lack of CD38 expression,,${ }^{1,2}$ human stem cells cannot be isolated to absolute purity. A number of in vitro culture systems have been developed to measure the proliferative and multilineage potential of hematopoietic precursors, ${ }^{3}$ but none of these assays suffices to measure stem cells among a mixed population of precursors. Therefore, the ability of human hematopoietic stem cells to reconstitute hematopoiesis in vivo remains the gold standard for measuring functional hematopoietic stem cells. $^{4}$

Efforts are ongoing to develop more suitable mouse strains that support human hematopoiesis and immune function. ${ }^{5}$ Among the first notable successes in this endeavor involved the transplantation of human hematopoietic tissues (liver and thymus or bone fragments) into mice with severe combined immunodeficiency, resulting in hematopoiesis mostly localized to the site of the xenograft. ${ }^{6,7}$ Use of mice with multiple mutations, causing greater immunodeficiency, allowed for seeding of the murine bone marrow (BM) by intravenous (i.v.) injection. ${ }^{8}$ A combined approach using fetal liver and thymus tissue grafts with i.v. fetal liver infusion has been used to yield complete hematolymphoid reconstitution in mice. ${ }^{9}$ NOD.Cg-Prkdc scid Il2 gg $^{\text {tmlWjil} / S z J ~(N S G) ~ m i c e ~ a r e ~}$ among the most recently developed variations of immunodeficient strains that support high levels of reconstitution with human cells owing to the complete lack of T-, B-, and NKcells in these animals. ${ }^{10}$ These mice are excellent recipients to study human hematopoiesis and immune function. ${ }^{11}$

Flow cytometry has been an important tool to evaluate human engraftment of mice. Early studies were limited to analysis of only a few simultaneous parameters owing to limitations in the availability of fluorochrome-conjugated monoclonal antibodies (mAbs) and the capabilities of the most commonly available flow cytometer. However, improvements in both reagents and instrumentation offer the possibility to advance the current means of detecting human cells engrafted in immunodeficient mice by staining samples with mAbs that distinguish murine and human cells. In concert, this expands the characterization of the engrafted cells to better understand the scope of human hematopoietic reconstitution. We probed the limitations of our current analytical tools to detect human chimerism and investi-
Correspondence: Marcus 0. Muench, Blood Systems Research Institute, 270 Masonic Ave., San Francisco, CA 94118, USA.

E-mail: mmuench@bloodsystems.org

Key words: hematopoietic stem cell, flow cytom etry, liver, chimeric mice, SCID mice.

Acknowledgements: the authors would like to extend their appreciation and recognition to the staff at the UCSF Medical Center for their contributions to the research. We thank Dale Hirschkorn for assistance with equipment, training, and management of the flow cytometry core. We also thank the administrative staff at our institute, in particular JoAnn Yates, Jerry Michaelson, Abigail Schrock, and Barbara Johnson. This work was supported by Blood Systems Inc., and grants from the National Institutes of Health: R21 HD055328, and support through the University of California San Francisco Liver Center (P30 DK026743).

Contributions: NLV acquired, analyzed, and helped interpret data (Figures 1-3); AB participated in the conception and design of the study, and helped in acquisition and interpretation of data (Figures 5-10); MEF participated in the acquisition of the data (Figures 1-10); MOM participated in the conception and design of the study, and contributed to the acquisition and interpretation of data (Figures 1-10). NLV and MOM contributed to drafting the manuscript, and $\mathrm{AB}$ and MEF contributed to revising it. All authors reviewed and approved the final manuscript.

Conflict of interests: the authors report no conflicts of interest.

Received for publication: 15 October 2010.

Revision received: 12 November 2010.

Accepted for publication: 12 November 2010.

This work is licensed under a Creative Commons Attribution 3.0 License (by-nc 3.0).

(C) Copyright N.L. Varga, et al., 2010

Licensee PAGEPress, Italy

Stem Cell Studies 2011; 1:e1

doi:10.4081/scs.2011.e1

gated which antigens are the most effective markers for evaluating multilineage reconstitution in several hematopoietic tissues.

\section{Materials and Methods}

\section{Experimental mice}

Mice were maintained in a restricted access, pathogen-free vivarium at the Blood Systems Research Institute. Founder NSG mice were obtained from Jackson Laboratories (Sacramento, CA, USA). The described research was performed with approval of the Institutional Animal Care and Use Committee at ISIS 
Services LLC (San Carlos, CA, USA). Mice were housed in sterile disposable microisolator cages within laminar flow racks (Innovive Inc., San Diego, CA, USA) and fed a sterile, irradiated diet of Harlan Rodent Global Diet 2919 (HarlanTeklad, Madison, WI, USA) with free access to sterile, irradiated water (Innovive Inc.). Sterile irradiated corn-cob bedding was used (Innovive Inc.) with autoclaved cotton Nestlets (Ancare, Bellmore, NY, USA), and GLP-certified Bio-Huts (Bio-Serv, Frenchtown, NJ, USA) provided for environmental enrichment. Entrance to the vivarium was limited to trained authorized personnel, and all husbandry and experimental procedures were performed within a laminarflow cage-changing station (NuAire, Plymouth, MN, USA).

\section{Human hematopoietic cells}

Fetal tissues were donated for research from elective abortions with the consent of the women undergoing the medical procedure and with approval of the University of California San Francisco's Committee on Human Research. Gestational age of specimens ranged from 18 to 24 weeks of amenorrhea; age was estimated from the foot length of the fetus. Human fetal bone marrow (FBM) was attained as the primary source of hematopoietic stem cells and progenitors for this study, and was procured and isolated as previously described. ${ }^{12}$ Light-density fetal liver cells depleted of mature blood cells were used as an additional source of hematopoietic precursors and were prepared as described. ${ }^{13}$

\section{Hematopoietic transplantation and tissue harvest}

NSG mice were irradiated with 175 or 200 cGy using an RS2000 X-Ray Biological Irradiator (RAD Source Technologies, Inc., Alpharetta, GA, USA) 1 to 3 hours before transplantation. Mice were transplanted i.v. by tail vein injection using a 28 -gauge U100 insulin syringe (BD, Franklin Lakes, NJ, USA) with $2 \times 10^{7} \mathrm{FBM}$ cells or $1 \times 10^{6}$ lineage-depleted fetal liver cells suspended in $200 \mu \mathrm{L}$ of phosphate buffered saline (PBS) (Mediatech, Inc., Manassas, VA, USA). After irradiation, the standard rodent diet was replaced with irradiated Global 2018 rodent diet with 4100 ppm Uniprim $^{\circledR}$ (Harlan-Teklad) for the first month after radiation treatment.

Mice were sacrificed by carbon dioxide asphyxiation followed by cervical dislocation at ages ranging from 12 weeks to 1.5 years. Human chimerism in NSG mice was analyzed $\geq 8$ weeks after transplantation as indicated in the text. BM was harvested by flushing the femurs of the mice with approximately $1 \mathrm{~mL}$ of culture medium using a syringe with a 27gauge needle (BD). Spleen and liver specimens were dissected and held in culture me- dium until cell isolation. All tissues were held on ice after harvest. NSG mice were examined at the time of tissue extraction for visible signs of poor health or physical abnormalities such as tumors of the liver, spleen, and thymus. Any moribund mice were removed from the study.

\section{Hematopoietic cell and tissue pro- cessing}

Mouse BM was washed by centrifugation for 7 minutes at $200 \mathrm{Xg}$ at $4^{\circ} \mathrm{C}$ and cells were resuspended in blocking buffer for staining with fluorochrome-conjugated mAbs. Blocking buffer consisted of PBS supplemented with $0.01 \% \mathrm{NaN}^{3}$ (Sigma Chemical Co., St. Louis, M0, USA), 5\% normal mouse serum (GeminiBio-Products, Inc., Woodland, CA, USA) and 2 $\mu \mathrm{g} / \mathrm{mL}$ rat anti-mouse CD16/CD32 mAb (BioLegend, San Diego, CA, USA).

Cell suspensions were prepared from mouse spleens by passage through a $40 \mu \mathrm{m}$ cell strainer (BD Biosciences, San Jose, CA, USA) in 1-2 $\mathrm{mL}$ PBS and layered on top of $1.077 \mathrm{~g} / \mathrm{mL}$ Lymphoprep (Axis-Shield PoC AS, Oslo, Norway). Cells were centrifuged at $600 \mathrm{X} g$ for 30 minutes at room temperature and the lightdensity fraction was collected. Collected cells were washed with PBS and resuspended in mouse blocking buffer.

Mouse liver cells were prepared by passage through a $40 \mu \mathrm{m}$ cell strainer and washed with PBS by centrifugation ( $7 \mathrm{~min}$ at $200 \mathrm{X} g$ at $4^{\circ} \mathrm{C}$ ). Cells were suspended in PBS, and light-density cells isolated, as for splenocytes and suspended in blocking buffer.

\section{Human bone marrow titrations}

To test the sensitivity of flow cytometry to enumerate chimerism, human FBM was mixed with BM from untransplanted NSG mice. Live cell concentrations were first approximated using a hemocytometer and trypan blue staining. A master mixture of approximately equal numbers of pure mouse and human cells was prepared and used for all further dilutions of the human cells with NSG-BM. In a second experiment, BM from a mouse engrafted with human FBM was used as a master mixture of cells. Triplicate or quadruplicate samples were seeded in a 96-well plate and 1:2 serial dilutions made with mouse BM. Cells were then stained with anti-human and anti-mouse mAbs as described. Samples of pure mouse and human cells were used as controls. Because hemocytometer cell counts have a low accuracy, we relied on the flow cytometric measurements of the frequencies of human cells in the master mixture and the degree of human cell dilution to establish the calculated percentage of human cells. Flow cytometry data typically contained $>10^{5}$ events/sample and are reported as the mean \pm standard error (SE) of individual measurements. The significance of differ- ences between samples was determined using the unpaired t-test (Aable 3.0 software, Gigawiz Ltd. Co., OK, USA), and differences were considered significant at $\mathrm{P} \leq 0.05$.

\section{Flow cytometry}

Cells suspended in blocking buffer and held on ice were stained with saturating levels of fluorochrome-labeled mAbs for at least 30 minutes. ${ }^{13}$ Table 1 lists the mAbs used in this study. Conjugated non-specific antibodies used as negative controls were purchased from Invitrogen, BD Biosciences and BioLegend. Samples were washed twice with PBS supplemented with $0.3 \%$ bovine serum albumin (Roche Diagnostic Corporation, Indianapolis, IN) and $0.01 \% \mathrm{NaN}_{3}$, and suspended in the same solution containing $2 \mu \mathrm{g} / \mathrm{mL}$ propidium iodide (PI; Invitrogen, Carlsbad, CA, USA). Samples were analyzed using an LSR II flow cytometer (BD Biosciences, San Jose, CA, USA). Data were analyzed using FlowJo software, version 8.8 (Tree Star, Inc., Ashland, OR, USA).

\section{Results}

\section{Optimizing the detection of mouse bone marrow cells}

Our goal was to devise panels of $\mathrm{mAb}$ for the analysis of human chimerism that dedicated a single fluorochrome channel to staining all murine BM cells and a single channel dedicated to detecting all human cells. Ideally, this would allow for the greatest possible separation of murine and human cells and exclusion of double-positive events that cannot be reliably classified as human or murine in origin. To allow the greatest flexibility in the choice of mAbs and fluorochrome conjugates to evaluate the human cells, the flow cytometry channels selected for marking pan-murine and panhuman cells should avoid using the most commonly applied fluorochromes such as fluorescein isothiocyanate (FITC), phycoerythrin (PE), and allophycocyanin (APC).

Preliminary studies indicated that three broadly expressed murine markers yielded strong staining when conjugated to pacific blue (PB): TER-119 (pan-erythrocyte), CD45 (panleukocyte), and $\mathrm{H}-2 \mathrm{~K}^{\mathrm{d}}$ (pan-nucleated cells) (Figure 1). Either CD45 or $\mathrm{H}-2 \mathrm{~K}^{\mathrm{d}}$ stained less than half of BM cells because of the large numbers of erythrocytes present in the tissue. Combining TER-119 and CD45 led to strong staining of nearly all BM cells with a noticeably higher mean fluorescence intensity (MFI) than staining with TER-119 and H-2Kd. Because $\mathrm{H}-$ $2 \mathrm{~K}^{\mathrm{d}}$ can stain non-hematopoietic cells present in the BM, we tested a combination of all three murine markers, which did yield the overall highest and brightest staining. 


\section{Optimizing the detection of human cells}

We evaluated a number of mAbs recognizing antigens found on a broad array of human hematopoietic cells (Figure 2). Although CD45, CD48, B2M, and anti-HLA-ABC could stain the majority of leukocytes and/or nucleated cells, only CD59 (protectin) alone could mark nearly all FBM cells. CD59 is expressed by mature erythrocytes seen as cells with a low forward light-scatter in Figure 2. Thus, we used CD59 mAb conjugated with AF700 to identify total human cells. We have found an initial screening of transplanted mice with a combination of CD34, CD45, CD59, and B2M to be useful in identifying which mice show signs of human reconstitution (Figure 2B). This panel of pan-leukocyte markers is further useful in identifying cases of low-level engraftment, because detection of a small number of positive events using only a single marker can result from non-specific staining of mouse BM cells, whereas co-expression in the particular pattern shown in Figure 2B indicates human engraftment. It is worth mentioning that B2M is a particularly bright marker of nucleated human cells with the brightness of staining using an FITC-conjugated $\mathrm{mAb}$ on par with staining using PE-conjugated CD45. B2M may be an ideal human marker of non-hematopoietic cell types transplanted in mice. The addition of CD34 to the panel allows one to gauge whether the presence of human cells is a result of hematopoietic engraftment or simply the presence of mature hematopoietic cells such as erythrocytes (CD59+CD45-B2M $\left.{ }^{-}\right)$or leukocytes (CD59+CD45 $\left.{ }^{+} \mathrm{B}^{\mathrm{M}}{ }^{+}\right)$.

\section{Defining the limits of human cell detection}

We performed titration experiments to determine the sensitivity of flow cytometry in detecting human cells among mouse BM cells (Figure 3). Human CD59+ cells were readily detected in diluted mixtures of human FBM and NSG-BM to levels below $1 \%$. The sensitivity of detecting human cells with CD59, CD45, or B2M was compared because staining with the latter two markers is generally brighter, offering greater differentiation from murine cells, than staining using CD59. Although CD45 and B2M staining could detect a significant presence of human cells below $0.04 \%$ (Figure $3 \mathrm{C}$ and $\mathrm{D}$ ), these results were equivalent to the sensitivity of CD59 staining (Figure $3 \mathrm{~B}$ ) in detecting the same level of FBM dilution. The weaker expression of CD59 was compensated for by the greater number of human events that could be detected, because CD59 is also expressed on erythrocytes. The effectiveness of using CD59 staining was confirmed further by measuring human cell engraftment of NSG-BM harvested 223 days after transplan-

Table 1. mAbs used in this study.

\begin{tabular}{|c|c|c|c|c|}
\hline \multicolumn{5}{|c|}{ mAbs recognizing widely-expressed human antigens } \\
\hline$\beta 2$-Microglobulin (B2M) & FITC & IgGl & 2M2 & BioLegend \\
\hline HLA-ABC & AF488 & IgGl & DX17 & BD Biosciences \\
\hline CD45 & PE & IgGl & HI30 & BioLegend \\
\hline CD45 & FITC & IgGl & $\mathrm{HI} 30$ & Invitrogen \\
\hline CD48 & PE & $\lg M$ & Tü145 & BD Biosciences \\
\hline \multirow[t]{2}{*}{ CD59 } & AF700 & IgG2a & p282(H19) & BioLegend \\
\hline & \multicolumn{4}{|c|}{ mAbs recognizing human progenitor and stem cell antigens } \\
\hline CD34 & APC & IgGl & 581 & BioLegend \\
\hline CD34 & $\mathrm{PE} / \mathrm{Cy} 7$ & IgGl & 581 & BioLegend \\
\hline CD38 & PE & IgGl & HB7 & BD Biosciences \\
\hline \multirow[t]{2}{*}{ CD133 } & APC & IgGl & $\mathrm{ACl} 33$ & Miltenyi Biotec Inc. \\
\hline & \multicolumn{4}{|c|}{ mAb recognizing human erythroid antigens } \\
\hline \multirow[t]{2}{*}{ CD235a } & APC & IgG2b & GA-R2 (HIR2) & BD Biosciences \\
\hline & \multicolumn{4}{|c|}{ mAbs recognivaing human myeloid antigens } \\
\hline CD14 & APC & IgGl & HCD14 & BioLegend \\
\hline CD15 & $P E$ & $\lg M$ & VlMC6 & Invitrogen \\
\hline CD33 & APC & IgGl & WM53 & BioLegend \\
\hline \multirow[t]{2}{*}{ CD66b } & FITC & $\lg M$ & G10F5 & BioLegend \\
\hline & \multicolumn{4}{|c|}{ mAbs recogniving human megakaryocyte and platelet antigens } \\
\hline CD4la & FITC & $\lg \mathrm{Gl}$ & HIP8 & BD Biosciences \\
\hline \multirow[t]{2}{*}{ CD42b } & PE & $\lg G 1$ & HIP1 & BioLegend \\
\hline & \multicolumn{4}{|c|}{ mAbs recognizing human B-cell antigens } \\
\hline CD19 & APC & $\lg \mathrm{Gl}$ & HIB19 & BioLegend \\
\hline CD20 & FITC & IgGl & L27 & BD Biosciences \\
\hline \multirow[t]{2}{*}{$\mathrm{CD} 22$} & $\mathrm{PE}$ & IgGl & HIB22 & BioLegend \\
\hline & \multicolumn{4}{|c|}{ mAbs recognizing human T- and NK-cell antigens } \\
\hline CD3 & PE/Cy7 & IgGl & UCHT1 & BioLegend \\
\hline CD4 & $P E$ & IgGl & L200 & BD Biosciences \\
\hline 2. & APC & IgGl & RPA-T8 & BD Biosciences \\
\hline \multirow[t]{2}{*}{ CD56 } & FITC & IgGl & HCD56 & BioLegend \\
\hline & \multicolumn{4}{|c|}{ mAb recognizing mouse antigens } \\
\hline & PB & Rat IgG2b & 30-F11 & BioLegend \\
\hline $\mathrm{H}-2 \mathrm{Kd}$ & PB & Mouse IgG2a & SF1-1.1 & BioLegend \\
\hline TER-119 & PB & Rat IgG2b & TER-119 & BioLegend \\
\hline
\end{tabular}

tation with FBM (Figure 3E). Significant detection of human cells occurred at a calculated dilution of $0.32 \%$ human cells.

\section{Doublet discrimination further improves the accuracy of human cell detection}

Chimeric mouse-human BM likely results in aggregates of mouse and human cells that may fail to be dispersed prior to analysis, leading to events expressing both mouse and human markers. We tested using doublet discrimination to remove cell clumps from analysis, ${ }^{14}$ utilizing BM from a chimeric animal with approximately even numbers of mouse and human cells (Figure 4). Plotting forward light-scatter height versus area enabled nearly $3 \%$ of doublet events to be eliminated from analysis, reducing the number of events stained with both human and murine markers.
Detection of human hematopoietic stem cell populations in the bone marrow and liver

Hematopoietic stem cells are a rare population of cells found among hematopoietic precursors expressing the highest levels of CD34 $\left(\mathrm{CD} 34^{++}\right),{ }^{15}$ expressing CD133, ${ }^{16}$ and exhibiting low/negligible levels of CD38 (CD38 $\left.{ }^{\text {low }}\right){ }^{17,18}$ In mice with robust human engraftment, a population of $\mathrm{CD} 34^{++} \mathrm{CD} 133^{+} \mathrm{CD} 38^{\text {low }}$ cells was readily detected in the BM (Figure 5). Even in cases of low level engraftment, these cells can be detected if a sufficient number of cells are analyzed. In one case in which we analyzed $>1.2$ million events, human engraftment was detected at $<0.2 \%$ and we observed a spectrum of cells expressing CD34, including CD $34^{++} \mathrm{CD} 133^{+} \mathrm{CD} 38^{\text {low }}$ cells representing $0.07 \%$ of human cells (data not shown). Such findings indicate that enumeration of 

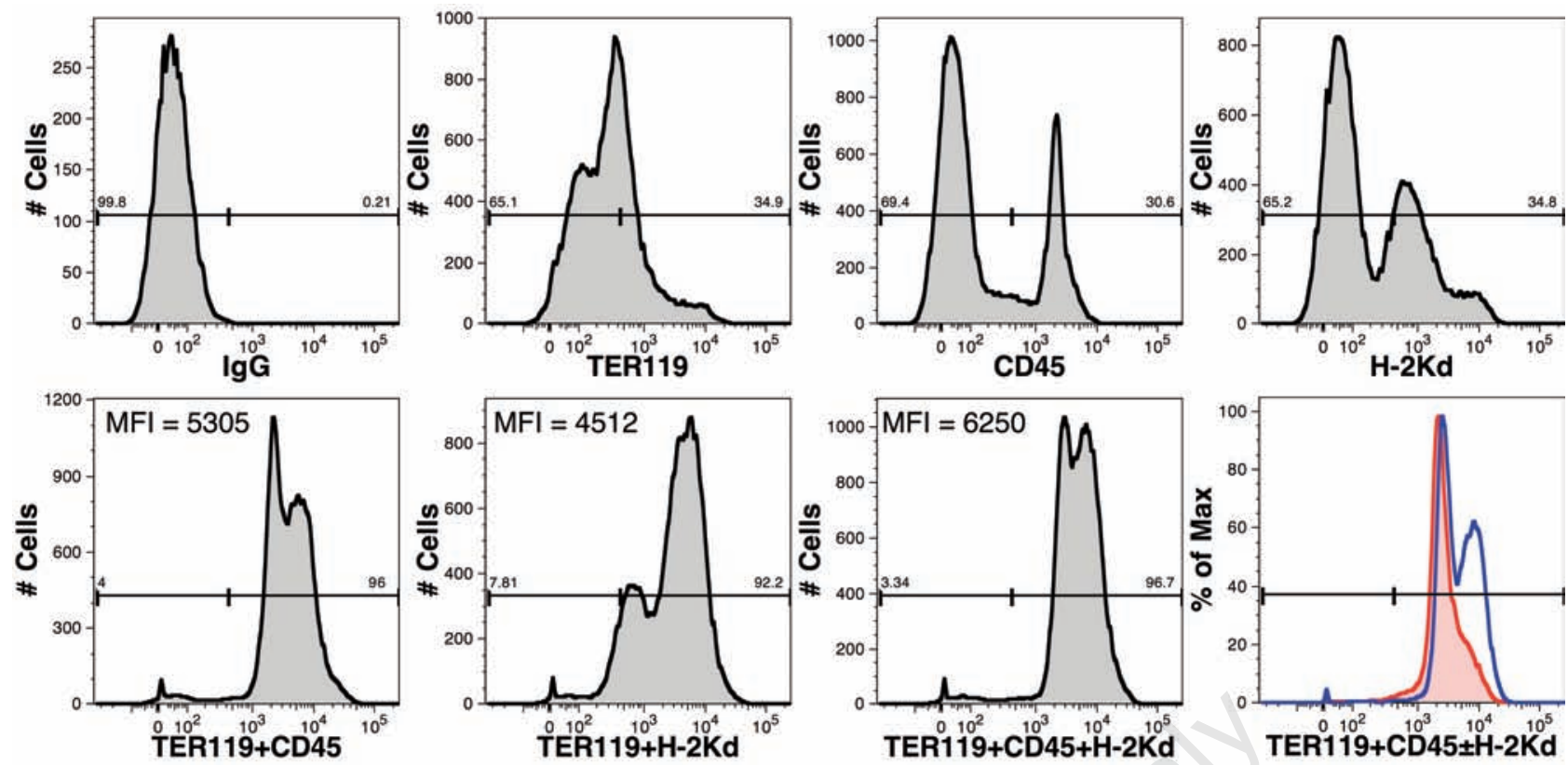

Figure 1. Comparison of cell-surface markers for the identification of mouse cells. The expression of TER-119, CD45 and H-2K ${ }^{\mathrm{d}}$ on $\mathrm{BM}$ cells isolated from an untransplanted NSG mouse was examined. All mAbs were conjugated to PB. Numbers above the gates represent the percentage of events falling within the gate. Additionally, the mean fluorescence intensity (MFI) is shown for cells stained with combinations of mAbs. An overlay of samples stained with TER119+CD45 (red line) and TER119+CD45+H-2 $\mathrm{K}^{\mathrm{d}}$ (blue line) is shown for a second independent sample of NSG-BM indicating that the highest intensity staining is achieved with all three mAbs.
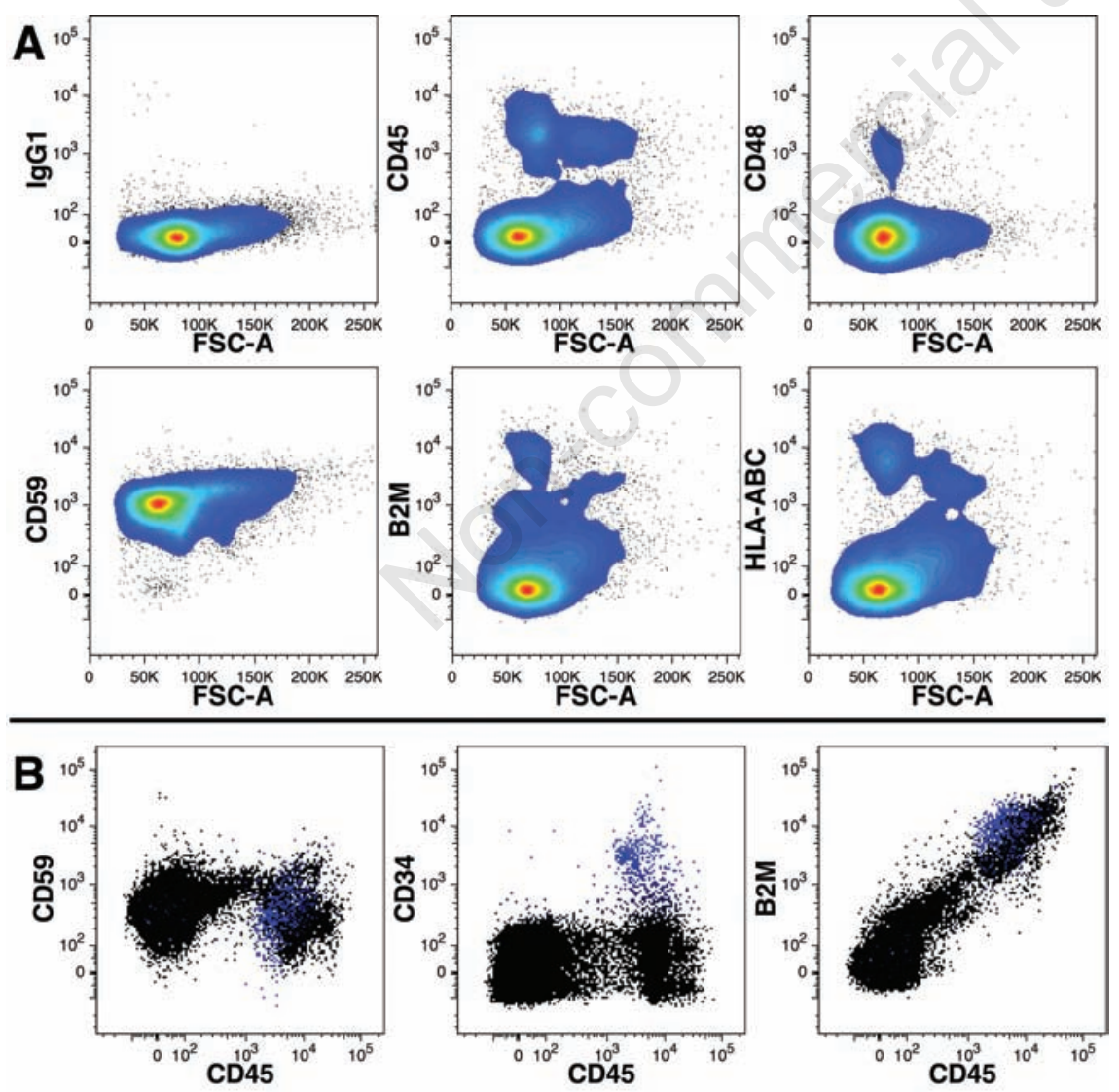

Figure 2. Comparison of cell-surface markers for the identification of human cells. Human FBM cells were stained for a panel of cell-surface markers widely expressed by hematopoietic cells (A). Note that only CD59 was expressed on nearly all events relative to control staining (IgG1). FBM cells were stained with B2M-FITC, CD45-PE, CD34APC, and CD59-AF700 (B). CD34 expression is shown in blue in all three dot-plots. hematopoietic stem cell populations is feasible even in mice with very low levels of human chimerism.

Interestingly, a typical phenotypic profile reflecting active hematopoiesis was also seen in the liver. A clearly defined population of $\mathrm{CD} 34^{++} \mathrm{CD} 133^{+} \mathrm{CD} 38^{\text {low }}$ cells was present as well as cells expressing lower levels of CD34 and higher levels of CD38 characteristic of committed hematopoietic progenitors. Similar results were observed in numerous mice analyzed whenever human engraftment was also detected in the BM. In contrast to the liver, very few, if any, CD34+/++ cells were observed in the spleens of engrafted mice.

\section{Detection of human erythrocytes}

Erythrocytes are readily detected by their specific antigen CD235a (glycophorin A) ${ }^{19}$ The relative small size of erythrocytes and their precursors can also be used to help reliably detect these cells by excluding large cells or cells with a high side-light scatter from consideration. Erythrocytes were detected based on these criteria in the BM of a mouse transplanted with FBM cells 229 days prior (Figure 6). $\mathrm{CD}_{235 \mathrm{a}^{+}}$cells were also observed among splenic cells, suggesting circulation of human erythrocytes. Note that light-density spleen cells were analyzed, thus likely reducing the number of mature erythrocytes detected because of their high density. CD235a expression increases during erythrocyte maturation and, accordingly, immature nucleated erythrocytes can be identified by their low level of 

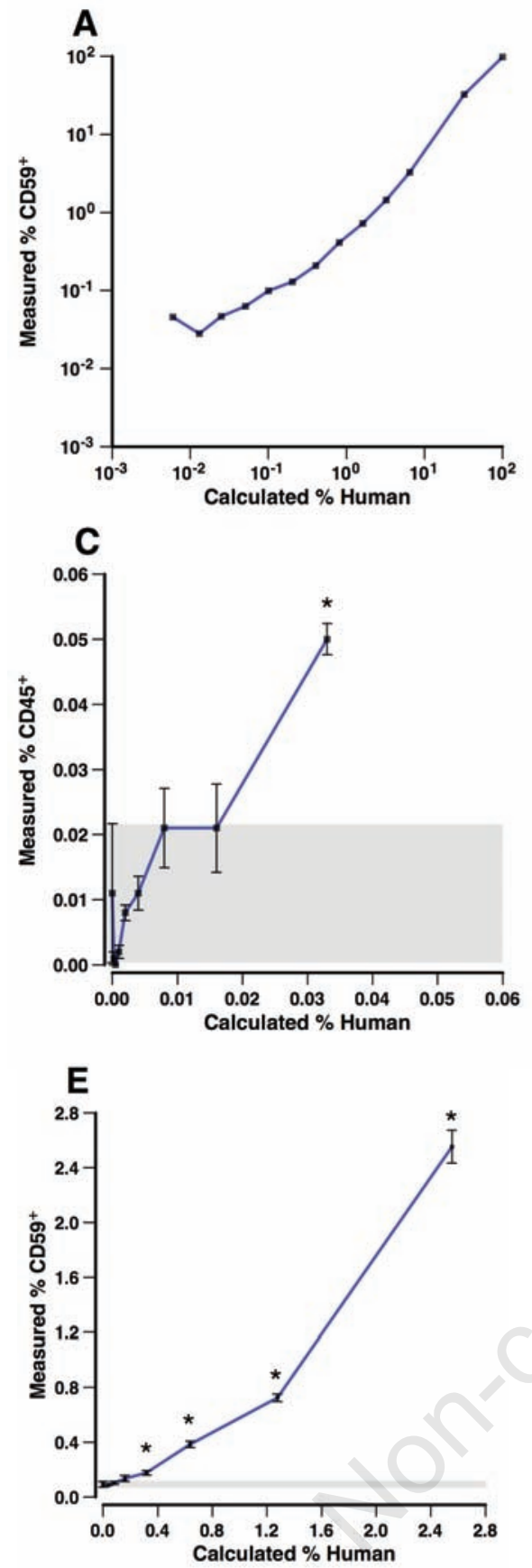

CD235a expression. Such cells were observed in the BM, but to a lesser extent in the spleen.

\section{Detection of human myeloid cells}

Myelopoiesis generates a number of cell lineages with distinct physical properties and cell antigen expression that can be distinguished by flow cytometry. We compared CD33 expression, a pan-myeloid cell antigen that has been used to define myeloid reconstitution, ${ }^{19}$ to expression of CD66b, CD14, and CD15 (Figure $7 \mathrm{~A})$. These three antigens are less widely expressed, with CD66b expression found on neutrophils,$^{20}$ high CD14 expression representing cells of the monocyte lineage ${ }^{21}$ and CD15
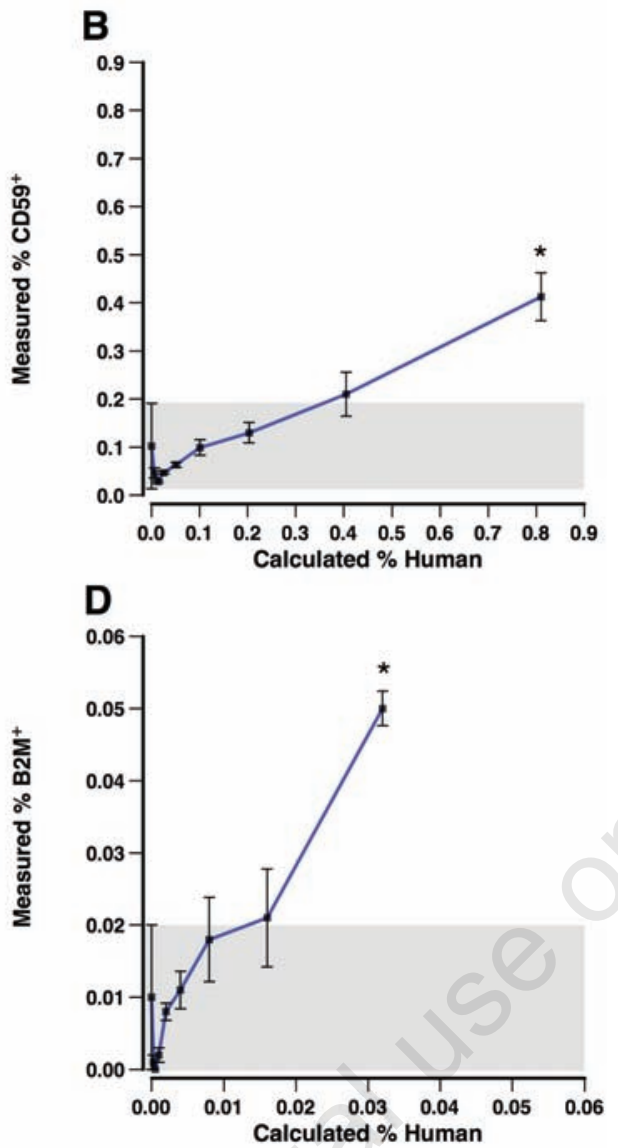

Figure 3. Sensitivity of flow cytometric detection of human fetal bone marrow cells mixed with mouse bone marrow. Human cells were analyzed alone or mixed with NSG-BM cells over a range of $0.006 \%$ to $100 \%$ calculated based on the dilution of human cells (A). Human cells were defined as CD59-AF700+ events that were negative for staining with $P I$ and the murine mAbs TER-119-PB, CD45-PB, and H-2Kd-PB. Note that the data are presented on a logarithmic scale. A subset of these data for dilutions containing $<1 \%$ human cells is shown in (B). Only in samples containing a calculated $0.81 \%$ human cells or higher was there a significant $(\mathrm{P} \leq \mathbf{0 . 0 5}$, asterisk) presence of human cells detected compared to samples of pure murine BM. A gray box indicates $1 \mathrm{SE}$ above and below the mean of the pure murine $\mathrm{BM}$ measurements $(n=3)$. The same samples shown in (B) were also stained with $\mathrm{CD} 45-\mathrm{PE}$ and B2M-FITC, for which the percentages of positive events are shown in (C) and (D), respectively. Detection of human $\mathrm{CD} 59^{+}$cells in $\mathrm{BM}$ harvested from an NSG mouse transplanted with human FBM diluted with varying amounts of untransplanted NSG$B M$ is shown in (E). Data are shown as the mean $\pm S E, n=3-4$ samples.

expressed on myeloid precursors and mature granulocytes. ${ }^{19}$ Each of these three antigens was expressed by a subset of CD $33^{+}$cells recovered from engrafted mice. The data also show that a subpopulation with the highest CD33 expression is not co-stained with either CD66b, CD14, or CD15, indicating that CD33 defines a larger population of human cells than can be detected by a combination of the three other antigens. Comparisons of CD66b, CD14, and CD15 co-expression revealed several populations of cells defined by these markers in chimeric mice (Figure 7B) and fresh human FBM (Figure 7C). In FBM, distinct CD14+ $\mathrm{CD}^{-}$CD66 $^{-}$monocytes and $\mathrm{CD}^{-} 4^{-} \mathrm{CD} 15^{+}$ $\mathrm{CD}_{66} \mathrm{~b}^{+}$granulocyte populations were evident, whereas in chimeric BM a similar pattern was observed as well as a population of cells expressing very high levels of CD66b and CD15, with a high side-light scatter profile, but lacking CD14 expression. There was an additional population of cells co-expressing CD66b and variable levels of CD14 (Figure 7B) that was not apparent in FBM. These data suggest some differences in myeloid antigen expression in mice engrafted with FBM compared to freshly harvested FBM.

We used the co-expression of two adhesion molecules, CD41 $\mathrm{a}^{22}$ and CD42b, ${ }^{23}$ to identify mature megakaryocytes and platelets in the $\mathrm{BM}$ and spleen of transplanted mice (Figure
8). $C D 41 a^{+} C D 42 b^{+}$events consistently represented a greater frequency of total human cells among light-density spleen cells than among total $\mathrm{BM}$ cells. CD41a $\mathrm{a}^{+} \mathrm{CD} 42 \mathrm{~b}^{+}$events in the spleen were represented by two distinctly sized populations as viewed using forward lightscatter (data not shown), presumably representing small platelets and larger megakaryocytes. In the BM, the $\mathrm{CD} 41 \mathrm{a}^{+} \mathrm{CD} 42 \mathrm{~b}^{+}$events were more evenly dispersed within the lightscatter gate used. $\mathrm{CD} 41 \mathrm{a}^{+} \mathrm{CD} 34^{+}$events were also detected in the BM in animals with robust reconstitution (data not shown). These progenitors have been reported to be enriched in megakaryocyte progenitors. ${ }^{24}$

\section{Detection of human lymphoid cells}

CD19 was used as the primary marker of the B-cell lineage (Figure 9). CD20, which is expressed in the latter stages of differentiation and by activated B-cells, was detected on CD19+ cells. CD22 (Siglec-2) is a B-cell marker expressed on early progenitors and mature cells, was also detected on $\mathrm{CD}^{+} 9^{+}$and CD19+CD34+ cells, indicating that the full range of human B-cell precursors can be observed in the reconstituted mouse BM.

T-cells were sometimes detected in transplanted mice, but most often only after $\geq 3$ months. Two examples of mice with full lymphoid reconstitution 229 days after FBM trans- 
Untransplanted NSG BM
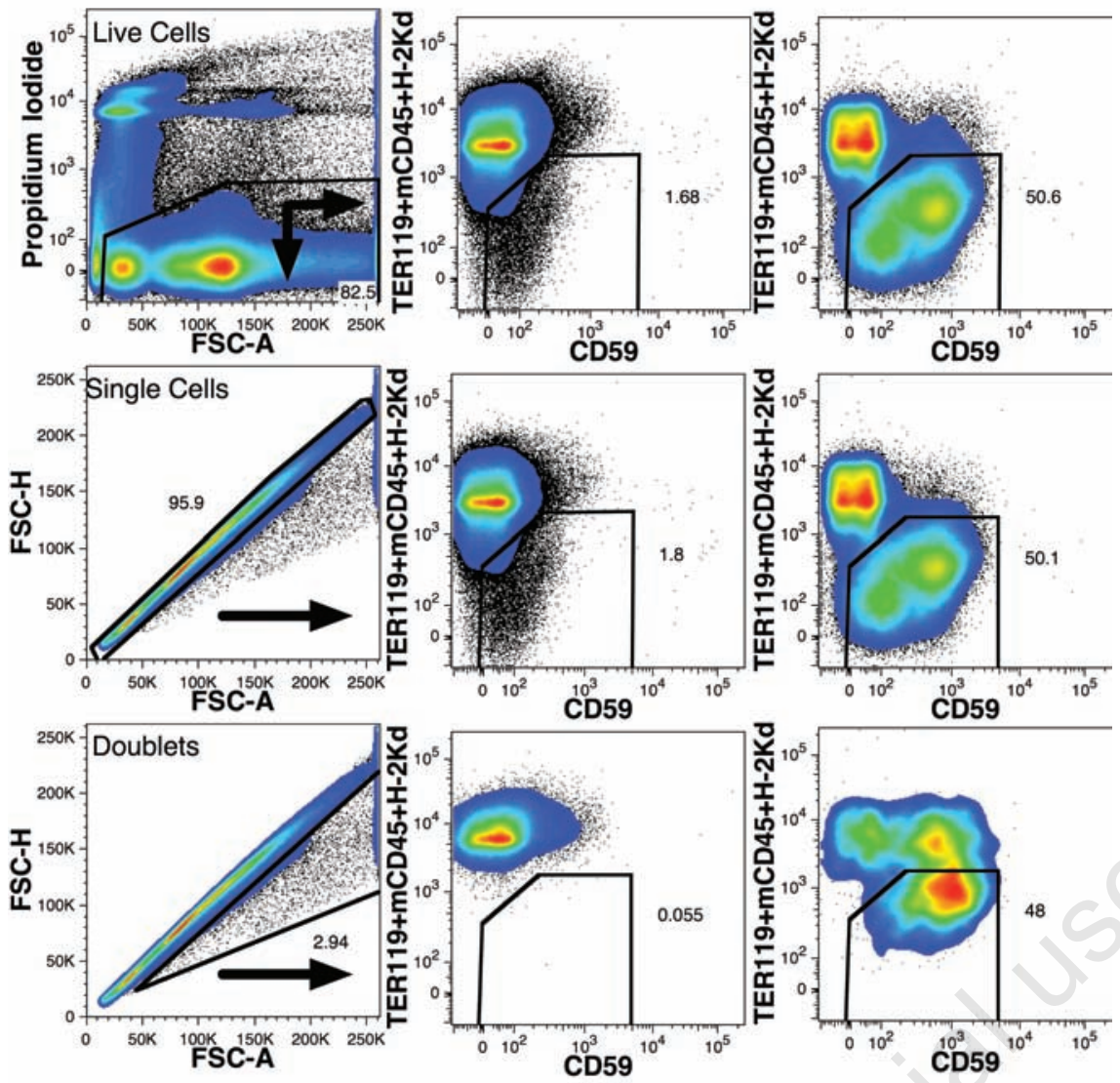

Figure 4. Improved detection of human cells in mouse bone marrow using doublet discrimination. A live cell gate was used to eliminate dead cells stained with PI as shown (top-left). Untransplanted NSG-BM (center column) and a mouse transplanted with human FBM 229 days prior (right column) were analyzed using only live cell gating (top row) or live cell gating and doublet discrimination (center row). The staining pattern of doublet mouse and/or human cells, excluded by the doublet discrimination, is shown in the bottom row. Numbers represent the percentage of cells that fall within the gated regions.
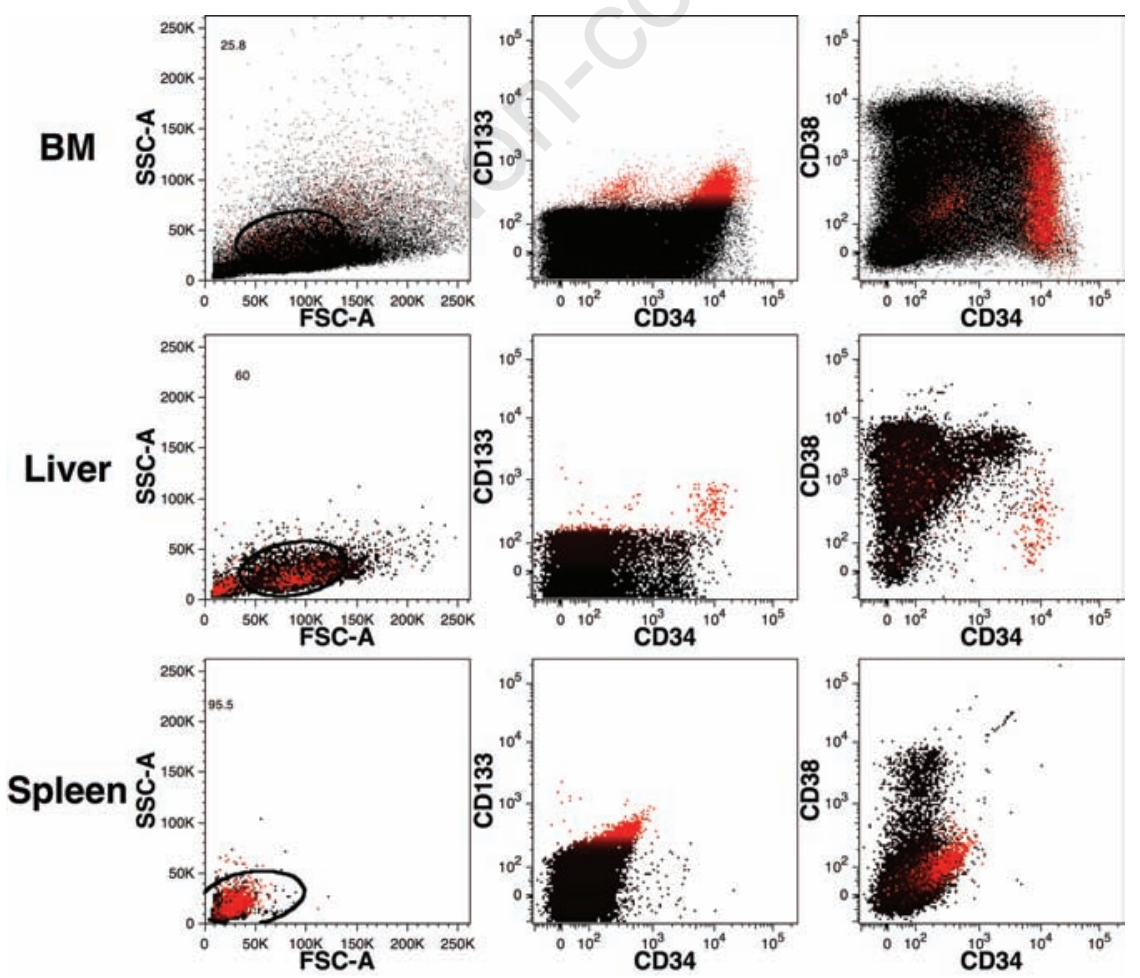

plantation are shown in Figure 10. T-cells were defined by their small size using a typical lymphoid-cell gate based on light-scatter properties and their expression of high levels of CD3 and CD45. CD4 and CD8 expression among these cells indicated that most of these T-cells were single positive cells, although some double positive events were observed. Tcells, when present, were more frequently observed among the human light-density splenocyte population than in the BM.

Natural killer (NK)-cells, defined as $\mathrm{CD} 6^{+} \mathrm{CD}^{-}$cells expressing high levels of CD45 (Figure 10), were infrequently detected. These cells were only observed in the BM of mice that exhibited otherwise robust multilineage human reconstitution. T-cells were more often detected than NK-cells. We have observed little or no expression of CD56 on $\mathrm{CD}^{+}$cells, thus most CD56 ${ }^{+}$events are likely to represent NK-cells. The expression of CD8 by some of the CD56 ${ }^{+}$cells further indicates that these cells are indeed NK-cells.

\section{Discussion}

The capacity of modern flow cytometers to analyze more than just a few fluorescence channels offers the ability to sensitively detect and better characterize human cells transplanted into immunodeficient mice. We describe a seven-color staining protocol that offers a high degree of specificity in detecting human cells and flexibility in choosing labeledmAbs to analyze the engrafted cells. Total human cells are detected by their expression of CD59 and their lack of strong staining by three markers of mouse cells: TER-119, CD45, and anti-H-2Kd Additionally, staining for cell viability using PI and use of doublet discrimination allows for accurate detection of human cells in mouse BM at levels below 1\%. Four fluorescence channels were used for lineage analysis of the human cells in our staining protocol, which is sufficient to perform a basic analysis of multilineage hematopoietic reconstitution

Figure 5. Detection of human hematopoi etic precursors in mouse bone marrow and liver. BM, liver, and spleen (rows top to bottom, respectively) were examined from a mouse transplanted 68-days prior with human lineage-depleted fetal liver cells. Hematopoietic precursors were stained with CD34-PE-Cy7, CD38-PE, and CD133-APC. CD133 staining is indicated in red, highlighting a population of probable hematopoietic stem cells in the BM and liver with the phenotype $\mathrm{CD} 33^{+} \mathrm{CD} 8^{\text {low }} \mathrm{CD} 34^{++}$. All data were gated for $\mathrm{PI}^{-} \mathrm{CD} 59^{+}$events excluding mouse cells as shown in Figure 4. 
BM
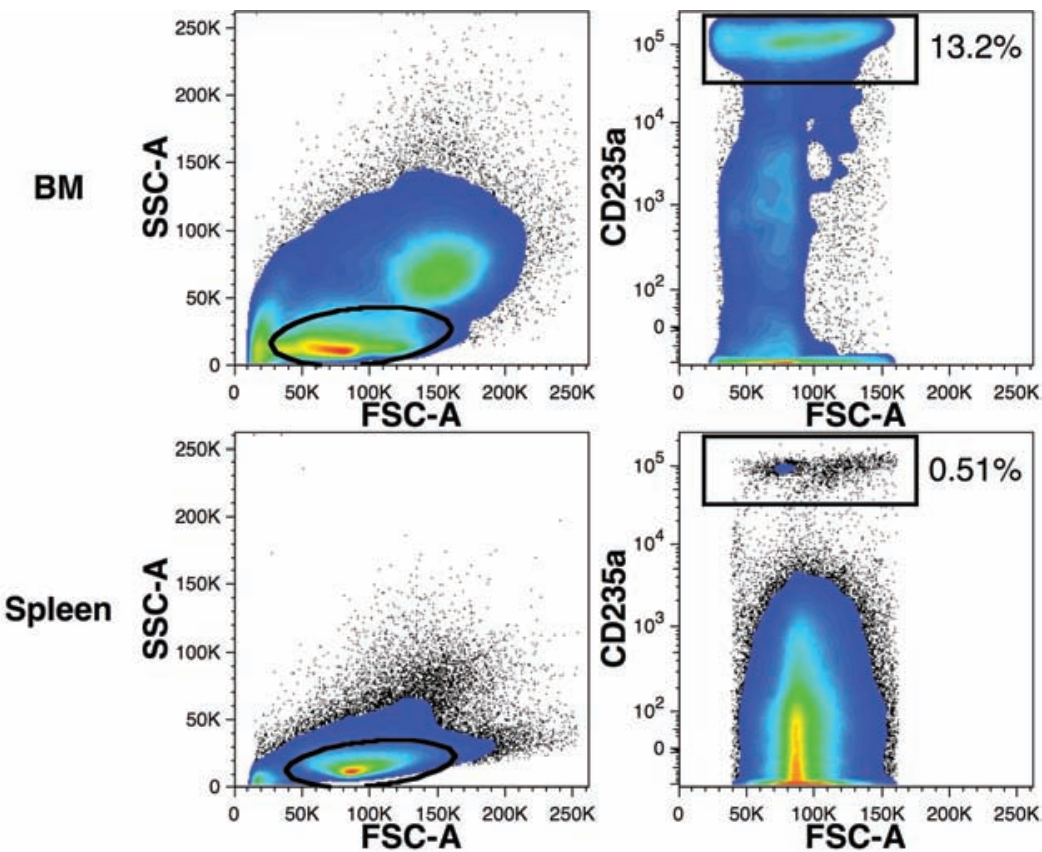

Figure 6. Detection of human erythrocytes in mouse hematopoietic tissues. Erythrocytes were detected using CD235a-APC staining of BM and spleen cells. These data were gated for PI-CD59+ events excluding mouse cells and doublets as shown in Figure 4. The percentages of total human $\mathrm{CD}_{59} 9^{+}$events expressing low levels of forward- and side-light scatter (ovals) and CD235a (rectangular regions) are indicated. in a single staining by evaluating the presence of erythroid (CD235 $\left.\mathrm{a}^{+}\right)$, myeloid (CD33+), Blymphoid $\left(\mathrm{CD} 19^{+}\right)$, and progenitor (CD34 $\left.{ }^{+/++}\right)$ cells. Such staining could be accomplished with a modest sample of BM reserving enough BM for other flow cytometric, molecular, or functional analyses.

Hematopoietic stem cells are defined by their capacity for long-term multilineage growth potential and a capacity for self-renewal. Although no criteria exist to specifically identify stem cells based on cell-surface antigen expression, a stem cell phenotype has been discerned that defines a population of cells greatly enriched for stem cells. We detected $\mathrm{CD} 34^{++} \mathrm{CD} 133^{+} \mathrm{CD} 38^{\text {low }}$ cells in the $\mathrm{BM}$ of engrafted mice, strongly suggesting the presence of hematopoietic stem cells. The use of multi-parameter flow cytometry to detect these cells offers stronger evidence for stem cell engraftment than is provided by the detection of CD34 ${ }^{+/++}$cells alone and provides the possibility to enumerate, isolate, and study these cells. Interestingly, we also observed a population of $\mathrm{CD} 4^{++} \mathrm{CD} 133^{+} \mathrm{CD} 38^{\text {low }}$ cells in the murine liver, but not the spleen. The adult spleen is an alternative site of hematopoiesis in mice when BM capacity is insufficient. ${ }^{25}$

\section{A}
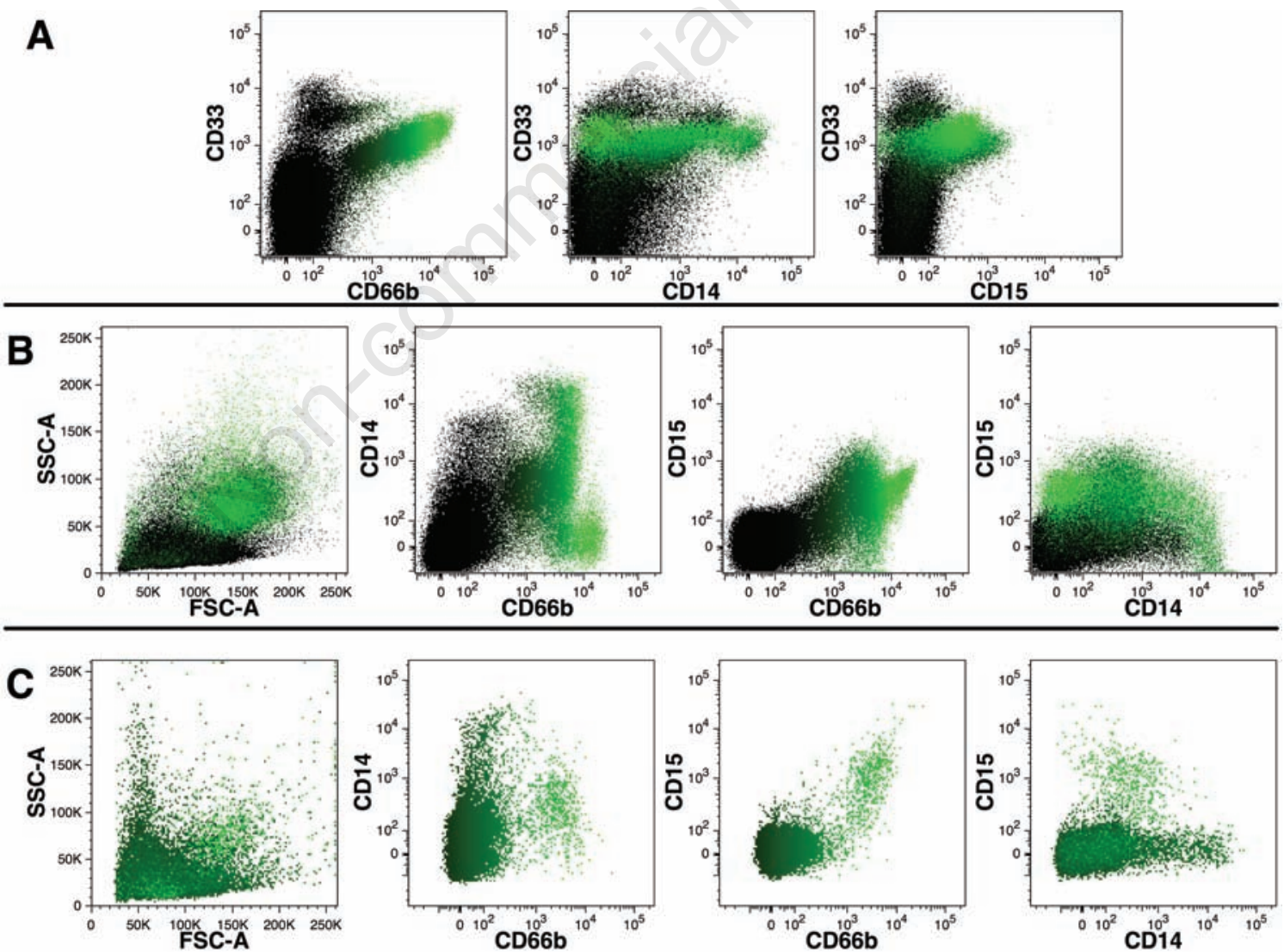

Figure 7. Detection of human myeloid cells in mouse bone marrow. (A) Expression of CD66b, CD14, and CD15 on CD33+ cells. (B) Coexpression patterns of CD66b, CD14, and CD15. Data in (A) and (B) were obtained using mouse BM harvested 229 days after transplant ation with human FBM and were gated for PI-CD59+ events excluding mouse cells and doublets as shown in Figure 4. (C) Co-expression patterns of CD66b, CD14, and CD15 staining of PI- human FBM. The intensity of CD66b-FITC staining is indicated by shades of green color in all dot-plots. 


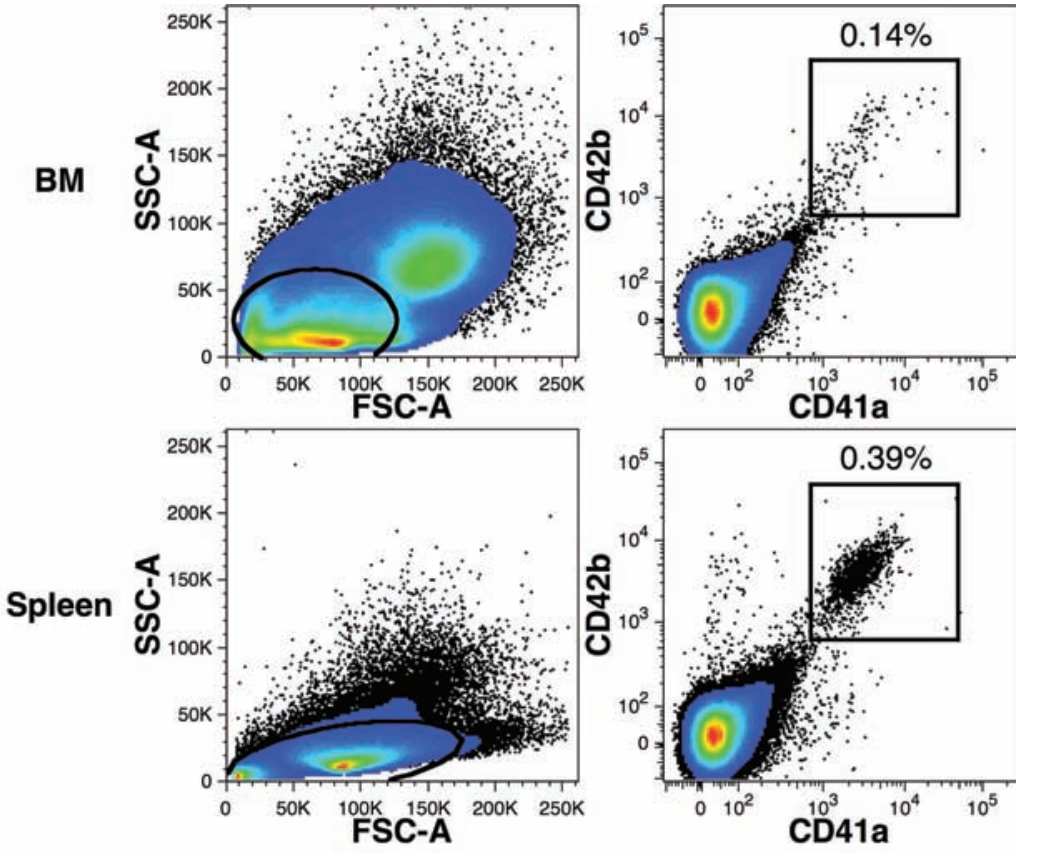

Figure 8. Detection of human megakaryocytes and platelets in mouse hematopoietic tissues. Data were collected from BM and light-density spleen cells gated for PI-CD $59^{+}$events and excluding mouse cells and doublets as shown in Figure 4. The percentages of total human $\mathrm{CD}_{59}{ }^{+}$events expressing low levels of forward- and side-light scatter (ovals) in addition to CD41a-FITC and CD42b-PE (rectangular regions) are indicated.
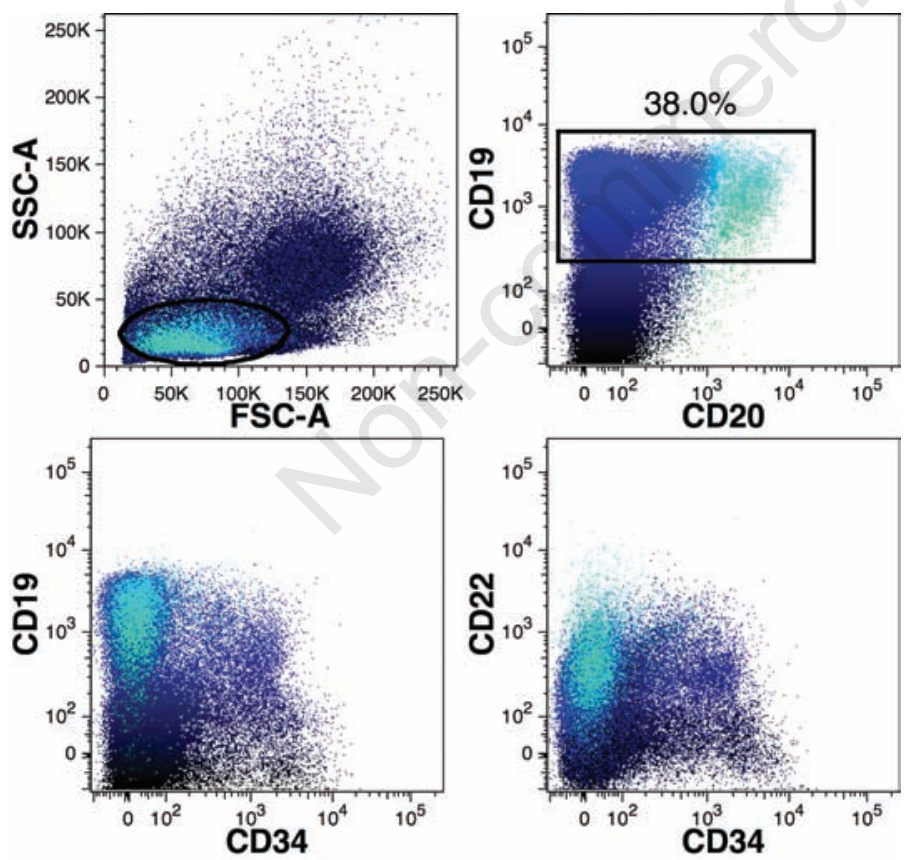

Figure 9. Detection of human B-lymphoid cells in mouse bone marrow. B-cells were primarily detected using CD19-APC expressing low levels of forward- and side-light scatter (oval gate) in addition to gating for $\mathrm{PI}-\mathrm{CD} 59^{+}$events excluding mouse cells and doublets as shown in Figure 4. The percentage of total human CD59+ events expressing CD19 (rectangular region) is indicated. BM cells were also co-stained with CD20-FITC, CD22-PE, and CD34-PC7. Co-expression of these markers is shown using polychromatic dot-plots in which $\mathrm{CD} 19^{+}$events are shown in dark blue and $\mathrm{CD} 19^{+} \mathrm{CD} 20^{+}$events are shown in light blue, as indicated in the top-right plot. Note the presence of $\mathrm{CD}^{-} 9^{+}$events among $\mathrm{CD} 34^{+}$ events and the predominance of CD20 expression among CD34- events.
Nonetheless, the spleen does not seem to support a significant population of human stem cells in an NSG mouse. Hematopoietic progenitors are known to be present in the adult liver. $^{26,27}$ Our findings show that the murine liver is a site of active extra-medullary hematopoiesis, as evinced by the spectrum of CD34 $4^{+++}$cells observed, and suggests that the liver may be a more important hematopoietic organ than the spleen in an otherwise healthy immunodeficient mouse. These findings encourage further study of the contribution of these liver precursors to normal and stressed hematopoiesis.

We evaluated myeloid differentiation using CD14 and CD15 or CD66b as markers of monocytes and neutrophils, respectively, rather than using the pan-myeloid antigen CD33. Detection of short-lived neutrophils would be a better indication of active hematopoiesis than measuring a heterogenous mixture of myeloid cells that includes longer-lived monocytes and macrophages. CD15 and CD66b were coexpressed in the BM of chimeric mice. Although populations of $\mathrm{CD}^{+} 4^{+}$(monocytes) and $\mathrm{CD}_{66 \mathrm{~b}^{+}}$(neutrophils) cells were observed in mice and FBM, additional populations of cells were identified by these markers in engrafted mice. CD14 expression is not exclusive to the monocyte lineage and has been reported to be weakly expressed on granulocytes such as neutrophils and basophils. ${ }^{28}$ CD66b expression on neutrophils can be increased by activation, ${ }^{20}$ and this carcinoembryonic antigen is also expressed on other granulocytes such as eosinophils ${ }^{29,30}$ and basophils. ${ }^{31}$ Thus, it appears that the mouse BM environment causes the activation and/or supports the development of granulocytes in an atypical manner.

Evidence of erythropoiesis and megakaryocytopoiesis was present in the BM and spleens of engrafted mice. The use of immunodeficient mice to study the development and survival of these cells is of interest to investigators studying gene therapy, ${ }^{32}$ ex vivo cell expansion, ${ }^{33,34}$ and hematopoietic transplantation. ${ }^{22}$ Unfortunately, the survival of human erythrocytes is poor in the murine circulation. ${ }^{32}$ We did observe CD235a $\mathrm{a}^{+}$cells in the spleen, but higher levels were detected in the BM with evidence of active erythropoiesis. Conversely, light-density splenocytes were more enriched for platelets/megakaryocytes than the BM and offer the most reliable method of detecting these cells in engrafted mice. Thrombocytopenia is associated with graft failure, ${ }^{35}$ so the ability to study the development of platelets in a mouse model is a welcome development.

Immunodeficient mice exhibiting full human hematopoietic reconstitution are of great interest to the study of human immunology and methods to treat and prevent disease. 

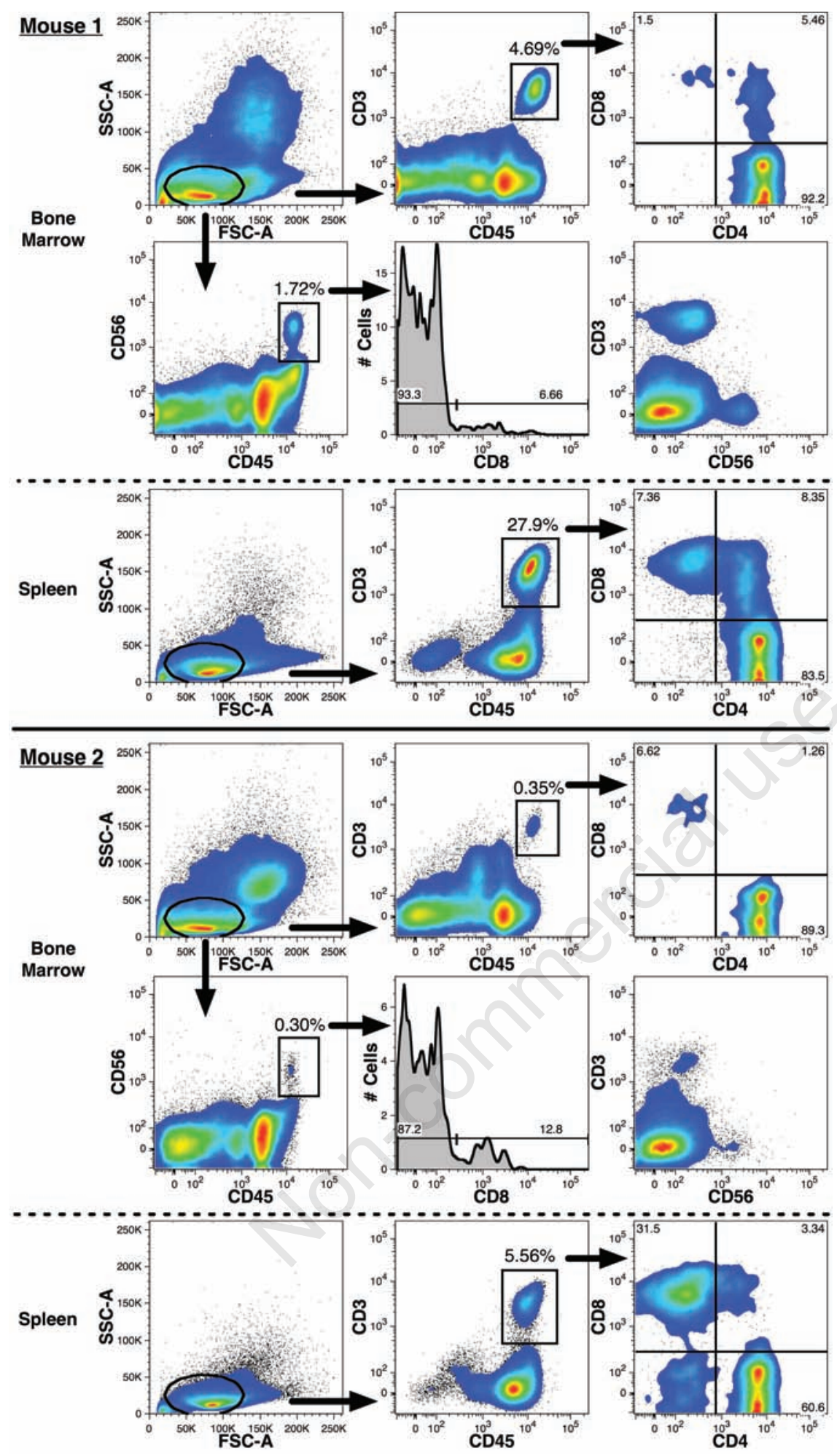

Figure 10. Detection of human T- and NK-lymphoid cells in mouse bone marrow. T-cells and NK-cells detected in two representative mice are shown. Both lymphoid lineages were defined by expression of low levels of forward- and side-light scatter (oval gates) in addition to gating for PI-CD59+ events excluding mouse cells and doublets as shown in Figure 4. High levels of CD45-FITC expression were also used to help distinguish the CD3-PC7 ${ }^{+}$ T-cells and CD56-PE ${ }^{+} \mathrm{NK}$-cells (rectangular gates). The respective frequencies of these two lineages among total human $\mathrm{CD} 59^{+}$events are indicated. T-cells were detected in both the $B M$ and among light-density spleen cells. The expression and frequency of CD4-PE and $\mathrm{CD} 8-\mathrm{APC}$ among $\mathrm{CD} 3{ }^{+} \mathrm{CD} 45^{+}$events are shown. $\mathrm{CD} 56^{+} \mathrm{CD} 45^{+}$events were only detected in the BM and the frequency of CD8 expression among these events are shown in the histograms. The mutually exclusive expression of CD3 and CD56 in the BM samples is also shown.
We observed B-, T-, and NK-cell development in NSG mice. B-lymphopoiesis in the BM is generally robust in engrafted mice comprising a large portion of the overall human hematopoietic output. ${ }^{10}$ Multiple stages of B-cell development were observed in the BM, but survival and normal function of B-cells outside the BM is known to be attenuated in chimeric mice because of species-restricted immune regulatory molecules. ${ }^{36}$ We observed that development of T- and NK-cells generally requires several months in adult mice. The spleen was consistently the best organ to detect T-cells, whereas NK-cells were only observed in the BM. $\mathrm{CD}^{+}{ }^{+} \mathrm{CD} 8{ }^{+} \mathrm{T}$-cells were detected in the spleen, and even the BM, suggesting extrathymic T-lymphopoiesis, albeit these cells could have developed elsewhere and migrated to these tissues. We further observed $\mathrm{CD}^{+}{ }^{+} \mathrm{CD} 8{ }^{+} \mathrm{T}$-cells in the thymus of younger mice as previously reported, ${ }^{10,11}$ but others did not report observing a prominent double positive T-cell population in the spleen. It is possible that this cell population does not arise in young mice and only develops in older mice in which the thymus gland has atrophied. It should be noted that T-cell development is improved when neonatal mice are transplanted, rather than adult mice transplanted in this study. ${ }^{11}$ Although cells with an NK-cell phenotype were observed in the BM, these cells were detected infrequently and their functional status remains unexplored. A complete understanding of the functional status and degree to which lymphoid reconstitution in NSG mice reflects the natural condition will require much further study, and multi-parameter flow cytometry is expected to play a salient role in this endeavor.

\section{References}

1. Xiao M, Dooley DC. Cellular and molecular aspects of human CD34+ CD38- precursors: Analysis of a primitive hematopoietic population. Leuk Lymphoma 2000;38:48997.

2. Bonnet D. Haematopoietic stem cells. J Pathol 2002;197:430-40.

3. Coulombel L. Identification of hematopoietic stem/progenitor cells: Strength and drawbacks of functional assays. Oncogene 2004;23:7210-22.

4. Shultz LD, Ishikawa F, Greiner DL. Humanized mice in translational biomedical research. Nat Rev Immunol 2007;7: 118-30.

5. Macchiarini F, Manz MG, Palucka AK, Shultz LD. Humanized mice: Are we there yet? J Exp Med 2005;202:1307-11.

6. McCune JM, Namikawa R, Kaneshima H, et al. The scid-hu mouse: Murine model 
for the analysis of human hematolymphoid differentiation and function. Science 1988;241:1632-9.

7. Kyoizumi S, Baum CM, Kaneshima H, et al. Implantation and maintenance of functional human bone marrow in scid-hu mice. Blood 1992;79:1704-11.

8. Kamel-Reid S, Dick JE. Engraftment of immune-deficient mice with human hematopoietic stem cells. Science 1988; 242:1706-9.

9. Melkus MW, Estes JD, Padgett-Thomas A, et al. Humanized mice mount specific adaptive and innate immune responses to EBV and TSST-1. Nat Med 2006;12:131622.

10. Shultz LD, Lyons BL, Burzenski LM, et al. Human lymphoid and myeloid cell development in NOD/tsz-scid IL2R gamma null mice engrafted with mobilized human hemopoietic stem cells. J Immunol 2005; 174:6477-89.

11. Ishikawa F, Yasukawa M, Lyons B, et al. Development of functional human blood and immune systems in NOD/SCID/IL2 receptor \{gamma\} chain(null) mice. Blood 2005;106:1565-73.

12. Golfier F, Bárcena A, Harrison MR, Muench MO. Fetal bone marrow as a source of stem cells for in utero or postnatal transplantation. Br J Haematol 2000;109:173-81.

13. Muench MO, Suskind DL, Bárcena A. Isolation, growth and identification of colony-forming cells with erythroid, myeloid, dendritic cell and NK-cell potential from human fetal liver. Biol Proced Online 2002;4:10-23.

14. Wersto RP, Chrest FJ, Leary JF, et al. Doublet discrimination in DNA cell-cycle analysis. Cytometry 2001;46:296-306.

15. DiGiusto D, Chen S, Combs J, et al. Human fetal bone marrow early progenitors for $\mathrm{T}$, $\mathrm{B}$, and myeloid cells are found exclusively in the population expressing high levels of CD34. Blood 1994;84:421-32.

16. Yin AH, Miraglia S, Zanjani ED, et al. AC133, a novel marker for human hematopoietic stem and progenitor cells. Blood 1997;90:5002-12.

17. Terstappen LW, Huang S, Safford M, Lansdorp PM, Loken MR. Sequential gen- erations of hematopoietic colonies derived from single nonlineage-committed CD34+CD38- progenitor cells. Blood 1991;77:1218-27.

18. Muench MO, Cupp J, Polakoff J, Roncarolo MG. Expression of CD33, CD38, and HLADR on CD34+ human fetal liver progenitors with a high proliferative potential. Blood 1994;83:3170-81.

19. van Lochem EG, van der Velden VH, Wind HK, et al. Immunophenotypic differentiation patterns of normal hematopoiesis in human bone marrow: Reference patterns for age-related changes and diseaseinduced shifts. Cytometry B Clin Cytom 2004;60:1-13.

20. Skubitz KM, Campbell KD, Skubitz AP. Cd66A, cd66b, cd66c, and cd66d each independently stimulate neutrophils. J Leukoc Biol 1996;60:106-17.

21. Ziegler-Heitbrock L. The CD14+ CD16+ blood monocytes: Their role in infection and inflammation. $\mathrm{J}$ Leukoc Biol 2007;81:584-92.

22. Mattia G, Milazzo L, Vulcano F, et al. Longterm platelet production assessed in NOD/SCID mice injected with cord blood CD34+ cells, thrombopoietin-amplified in clinical grade serum-free culture. Exp Hematol 2008;36:244-52.

23. Erlandsen SL, Greet Bittermann A, White J, Leith A, Marko M. High-Resolution cryofesem of individual cell adhesion molecules (cams) in the glycocalyx of human platelets: Detection of p-selectin (CD62P), GPI-IX complex (CD42A/CD42B alpha, B beta), and integrin gpiibiiia (CD41/CD61) by immunogold labeling and stereo imaging. J Histochem Cytochem 2001;49:80919.

24. Murray LJ, Mandich D, Bruno E, et al. Fetal bone marrow CD34+CD41+ cells are enriched for multipotent hematopoietic progenitors, but not for pluripotent stem cells. Exp Hematol 1996;24:236-45.

25. Kim $\mathrm{CH}$. Homeostatic and pathogenic extramedullary hematopoiesis. J Blood Med 2010;1:13-19.

26. Watanabe H, Miyaji C, Seki S, Abo T. CKit+ stem cells and thymocyte precursors in the livers of adult mice. J Exp Med
1996;184:687-93.

27. Crosbie OM, Reynolds M, McEntee G, et al. In vitro evidence for the presence of hematopoietic stem cells in the adult human liver. Hepatology 1999;29:1193-8.

28. Jersmann HP. Time to abandon dogma: CD14 is expressed by non-myeloid lineage cells. Immunol Cell Biol 2005;83:462-7.

29. Eades-Perner AM, Thompson J, van der Putten H, Zimmermann W. Mice transgenic for the human CGM6 gene express its product, the granulocyte marker cd66b, exclusively in granulocytes. Blood 1998;91:663-72.

30. Torsteinsdóttir I, Arvidson NG, Hällgren R, Håkansson L. Enhanced expression of integrins and cd66b on peripheral blood neutrophils and eosinophils in patients with rheumatoid arthritis, and the effect of glucocorticoids. Scand J Immunol 1999;50:433-9.

31. Watkins NA, Gusnanto A, de Bono B, et al. A haematlas: Characterizing gene expression in differentiated human blood cells. Blood 2009;113:e1-9.

32. Hayakawa J, Hsieh MM, Anderson DE, et al. The assessment of human erythroid output in NOD/SCID mice reconstituted with human hematopoietic stem cells. Cell Transplant 2010, Jun 29. [Epub ahead of print.]

33. Neildez-Nguyen TM, Wajcman H, Marden MC, et al. Human erythroid cells produced ex vivo at large scale differentiate into red blood cells in vivo. Nat Biotechnol 2002;20:467-72.

34. Schipper LF, van Hensbergen Y, Fibbe WE, Brand A. A sensitive quantitative singleplatform flow cytometry protocol to measure human platelets in mouse peripheral blood. Transfusion 2007;47:2305-14.

35. Bruno B, Gooley T, Sullivan KM, et al. Secondary failure of platelet recovery after hematopoietic stem cell transplantation. Biol Blood Marrow Transplant 2001;7:15462.

36. Schmidt MR, Appel MC, Giassi LJ, et al. Human BLyS facilitates engraftment of human PBL derived B cells in immunodeficient mice. Plos ONE 2008;3:e3192. 